\title{
Application of low-temperature thermal treatment for the reduction of mercury content in coal
}

\author{
Michał Wichliński ${ }^{1, a}$,Rafał Kobyłecki ${ }^{1}$ and Zbigniew Bis ${ }^{1}$ \\ ${ }^{1}$ Energy Engineering Department, Faculty of Infrastructure and Environment, Czestochowa University of Technology, Poland
}

\begin{abstract}
The article describes research carried out on four coals samples (raw coals A and B and enriched coals A and B). The fuels were subjected to low-temperature thermal treatment in order to remove as much mercury as possible while still maintaining high energy quality of the fuels. The lab-scale tests were performed in a fluidized

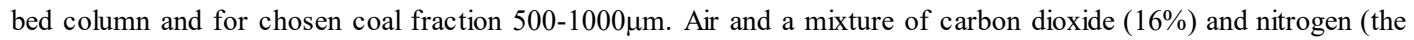
rest) were used as the fluidizing medium that as intended to have similar composition as the synthetic flue gas. The coals were tested for five temperatures of $200,250,300,350$ and $400^{\circ} \mathrm{C}$. The results indicated that it was possible to remove more than $80 \%$ of mercury from coal A (raw and enriched), in $\mathrm{CO}_{2} / \mathrm{N}_{2}$ atmosphere at the temperature of $400^{\circ} \mathrm{C}$ in the case of coal B, both raw and enriched, the amount of removed mercury at $400^{\circ} \mathrm{C}$ was roughly $70 \%$. At lower temperature, $350^{\circ} \mathrm{C}$, the amount of removed mercury was $70 \%$ and $60 \%$ for coals $\mathrm{A}$ and $\mathrm{B}$, respectively. Apart from the above test the investigation were also carried out in order to determine the loss of volatiles during the thermal treatment of the coals. The results indicated that at $400^{\circ} \mathrm{C}$ roughly $20 \%$ of the volatiles were evolved from the fuel particles. The loss of elemental carbon and fuel higher heating value (HHV) after the treatment were $10 \%$ and $8 \%$, respectively.
\end{abstract}

\section{Introduction}

The reduction of pollutant emission to the atmosphere is now one of the most important challenges for power plants. Apart from getting rid of compounds such as $\mathrm{SO}_{2}$, or $\mathrm{NO}_{\mathrm{x}}$, several attempts are carried out nowadays to minimize the emission of other compounds such as $\mathrm{CO}_{2}$ and mercury. The latter one is emitted to the atmosphere mainly from the combustion of coal and its contribution to the total emission is estimated at roughly $40 \%$ of the world mercury emission [1]. The contribution of power plant emission is particularly significant in countries like Poland where more than 63 million tons of lignite and over 73 million tons of hard coal have been mined recently [2] and where over $80 \%$ of electricity is produced in hard coal or lignite fired facilities. In 2014, Poland produced approximately 159 TWh of electricity of which more than 74 TWh where generated from hard coal and over $51 \mathrm{TWh}$ from lignite. The recently reports indicate that mercury content in coal in the world varies significant and, in some extreme cases, could reach up to $1000 \mathrm{ng} / \mathrm{g}$ [3]. The Polish coals were also examined and several authors report that the average mercury content in Polish hard coals combusted for power generation is roughly $80 \mathrm{ng} / \mathrm{g}$ [4-7]. Even though $\mathrm{Hg}$ content in Polish is relatively low. Poland is one of the biggest emitters of mercury in Europe with the emission of more than 10 tons/year due to large quantity of coal burned. Głodek and Pacyna [8] report that the emission of mercury from a single Polish power

\footnotetext{
${ }^{a}$ Corresponding author: michal.wichlinski@gmail.com
}

plant may be even $50 \mathrm{~kg} \mathrm{Hg} /$ year. There are two main groups of methods to reduce mercury emissions to the atmosphere. The first group called 'postcombustion methods' depend on the removal of mercury from the flue gas after the combustion process and the most common sorbent used for this purpose is activated carbon impregnated with sulfur or iodine. The second group of methods called 'precombustion methods' is focused on mercury removal from the fuel before its combustion in power plants. Those methods are briefly described in the publication of Wichliński and others [9]. Particular focus is put to a low temperature thermal treatment of fuel (LT3). The LT3 technology involves the exposition of the fuel to temperature high enough to remove majority of mercury, without significant degradation of coal as a fuel. Except for the removal of mercury, an advantage of this method is also the removal of fuel moisture particularly advantageous in the case of high moisture fuels. The effectiveness of this method depends mainly on the type of mercury compounds in coal (mainly: $\mathrm{HgO}, \mathrm{HgO}_{2}, \mathrm{Hg}_{3}\left(\mathrm{SO}_{4}\right) \mathrm{O}_{2}$, $\mathrm{Hg}_{2} \mathrm{SO}_{4}, \mathrm{HgCl}_{2}$ as presented by Uruski and others [11]). Except for $\mathrm{HgO}$ the decomposition temperatures of the above compounds are below the ignition temperature of coal. Accordingly mercury can be released from the fuel before the ignition of coal. Preliminary results indicate [11-16] more than $90 \%$ of mercury may be removed at temperatures roughly $400^{\circ} \mathrm{C}$. Despite such temperature, the reduction of volatile matter and higher 
heat value may be controlled and maintained at low level (Zarzycki and Wichliński [17]). The main goal of this paper is to provide some information on the LT3 technology and corresponding results.

\section{Research methodology}

\subsection{Coal data}

For the present studies four coal samples were selected. All of them were hard coals, form Polish mines. Two of them were raw fuels (coals ' $A$ ' and 'B'), and the other two were enriched coals (coals ' $A$ ' and ' $B$ '). The results of the coal analysis are shown in Table 1.

Table 1. Some main parameters of the coal samples used in the experiments (all values are given as 'air dry')

\begin{tabular}{|l|c|c|c|c|c|}
\hline & Unit & $\begin{array}{c}\text { Coal } \\
\text { A } \\
\text { raw }\end{array}$ & $\begin{array}{c}\text { Coal A } \\
\text { enriched }\end{array}$ & $\begin{array}{c}\text { Coal } \\
\text { B } \\
\text { raw }\end{array}$ & $\begin{array}{c}\text { Coal B } \\
\text { enriched }\end{array}$ \\
\hline $\begin{array}{l}\text { Transient } \\
\text { moisture }\end{array}$ & $\%$ & 9,3 & 5,3 & 10,3 & 8,1 \\
\hline $\begin{array}{l}\text { Hygroscopic } \\
\text { moisture }\end{array}$ & $\%$ & 3,4 & 3,4 & 3,5 & 4,4 \\
\hline Ash & $\%$ & 28,1 & 12,6 & 32,6 & 22,3 \\
\hline $\begin{array}{l}\text { Volatile } \\
\text { matter }\end{array}$ & $\%$ & 24,0 & 29,4 & 23,8 & 27,1 \\
\hline $\begin{array}{l}\text { Fixed } \\
\text { carbon }\end{array}$ & $\%$ & 44,5 & 54,6 & 40,1 & 46,1 \\
\hline HHV & $\mathrm{kJ} / \mathrm{kg}$ & 22600 & 28100 & 20300 & 23800 \\
\hline LHV & $\mathrm{kJ} / \mathrm{kg}$ & 21700 & 27000 & 19500 & 22800 \\
\hline $\mathrm{C}$ & $\%$ & 54,1 & 67,4 & 49,4 & 56,3 \\
\hline Hg & $\mathrm{ng} / \mathrm{g}$ & 76 & 75 & 146 & 124 \\
\hline
\end{tabular}

\subsection{Experimental facility}

The experiments of low-temperature thermal treatment (LT3) were conducted on a fluidized bed reactor. Diagram of a fluidized bed reactor was shown in Fig. 1. The bed solids were composed of quartz sand (particle size $250-500 \mu \mathrm{m})$ and $10 \mathrm{~g}$ of ceramic balls $(\mathrm{dp}=1,6 \mathrm{~mm})$. Depending on the type of experiments, a fluidizing medium was air, or a mixture of nitrogen (84\%) and carbon dioxide (16\%).

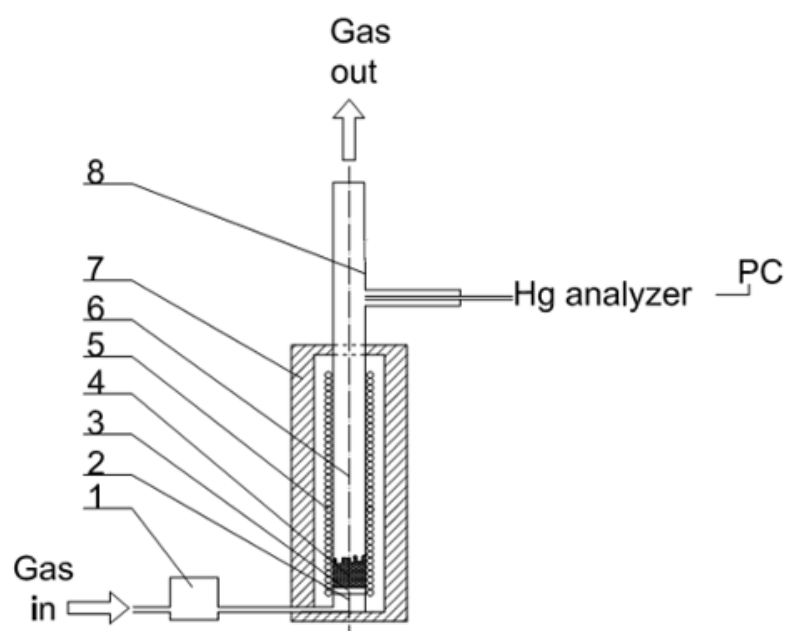

Figure 1. Sketch of the fluidized bed column: 1-mass/gas flow controller, 2-gas distributor,3-grate, 4 -fluidized bed, 5-electric heater, 6- quartz tube, 7-thermal insulation, 8measurement zone.
Regardless of the type of fluidization medium, maintained the same flow of gas volume of $10 \mathrm{dm}^{3} / \mathrm{min}$. The temperature in the fluidized bed column was controlled and adjusted using a thermocouple and adjusted by an electronic controller. For each test 0.5 $\mathrm{g}$ of coal of particle size between 500 and $1000 \mu \mathrm{m}$ was introduced into the bed. After the introduction of the sample into the reactor the mercury compounds contained in the coal decomposed. The evolved gases were mixed with fluidizing gas and the $\mathrm{Hg}$ content in gas mixture was analysed on-line by the LUMEX RA-915+ spectrometer connected to the system properly prepared test point. The output signals are connected to a computer, which allowed for registration of the measured values. The details on the mercury spectrometer are published elsewhere [18].

The degree of mercury release from coal sample was calculated by integrating the area under the curve of instantaneous mercury concentrations. The calculated value was then substituted into formula (1), to calculate the amount of mercury released during thermal treatment of coal at various temperatures. Eq.(1) allows to determine the mercury concentration in the solid sample from the integration of the area under the mercury concentration curve:

$$
S_{H g}=\frac{144 F p_{H g} \dot{V}_{g}}{m_{p r}}
$$

where: $S_{H g}$ is the mercury content in the sample $[\mathrm{ng} / \mathrm{g}]$, $F p_{H g}$ is the area under the mercury emission curve, $\left[\left(\mathrm{ng} / \mathrm{m}^{3} \mathrm{n}\right) \mathrm{s}\right], 144$ is a constant factor, $m_{p r}$ is the mass of the sample [g], and $\dot{V}_{g}$ is the gas flow rate $\left[\mathrm{m}^{3} \mathrm{n} / \mathrm{s}\right.$ ].

After the bed was cooled down the remaining coal sample was then removed and combusted in a pyrolysis snap-RP-91c connected to the spectrometer RA-915+. The sum of mercury released during the thermal treatment of coal in the fluidized bed at a given temperature and the mercury released during the combustion in the pyrolytic snap at $850{ }^{\circ} \mathrm{C}$ was assumed as the total mercury content in the coal sample. The degree of mercury release during thermal treatment of coal was then calculated as a mass ratio of mercury released during coal thermal treatment at a given temperature to the total mercury in the sample.

\section{Results and discussion}

\subsection{The release of mercury from coal}

The research were carried out in air and $\mathrm{CO}_{2} / \mathrm{N}_{2}$ mixtures, and for a selected fuel fraction of $500-1000 \mu \mathrm{m}$. The results of mercury release were shown in figure 2 . For As can be seen coal A (raw) even at $250^{\circ} \mathrm{C}$ it was possible to remove roughly $30 \%$ of mercury in air while, for coal A (enriched) roughly $35 \%$ of $\mathrm{Hg}$ was removed. At a higher temperature $\left(300^{\circ} \mathrm{C}\right)$ was removed nearly $70 \%$ mercury from coal A (raw) already, while only $55 \%$ from coal A (enriched). Further increase at temperature $350^{\circ} \mathrm{C}$ to brought about that $70 \%$ of $\mathrm{Hg}$ was evolved from both types of coal A (raw and enriched). For the highest 
temperature $\left(400^{\circ} \mathrm{C}\right)$ the amount of released mercury increased to $80 \%$ for both coal $\mathrm{A}$ (raw and enriched). The replacement of air with $\mathrm{CO}_{2} / \mathrm{N}_{2}$ mixture favored the release of mercury and over $65 \%$ of $\mathrm{Hg}$ was evolved from raw coal A already at $250^{\circ} \mathrm{C}$. At $300^{\circ} \mathrm{C}$ over $80 \%$ and $75 \%$ of $\mathrm{Hg}$ was released from raw and enriched coal A, respectively.

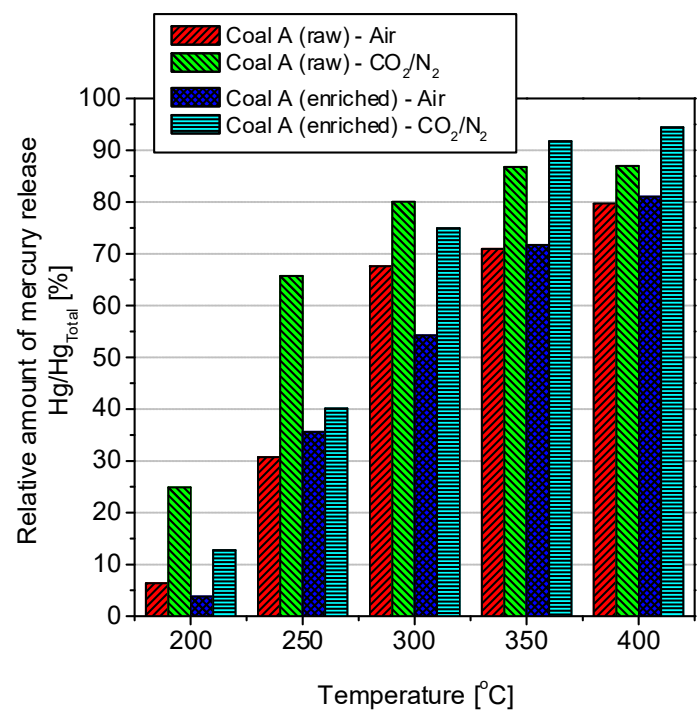

Figure 2. Relative amount of mercury release in selected temperature for coal A

The corresponding values for thermal treatment at $350^{\circ} \mathrm{C}$ are $90 \%$ (enriched coal $\mathrm{A}$ ) and $85 \%$ (raw coal A). In the highest temperature $\left(400^{\circ} \mathrm{C}\right)$ the amount of mercury released was similar and yielded at roughly $85 \%$ (coal A - raw) and 95\% (coal A - enriched).

In the case of coal $\mathrm{B}$ at $250^{\circ} \mathrm{C}$ (fig. 3) and air atmosphere the amount of mercury released was just $15 \%$ for both types (raw and enriched) coals while at $300{ }^{\circ} \mathrm{C}$ over $55 \%$ and over $40 \%$ of $\mathrm{Hg}$ was reduced from raw and enriched coal $\mathrm{B}$ respectively. For the temperature of $350^{\circ} \mathrm{C}$, the corresponding values were $65 \%$ (coal B raw) and 55\% (coal B - enriched). The change of atmosphere form air to $\mathrm{CO}_{2} / \mathrm{N}_{2}$ mixture has also positively affected the process of mercury removal as can be concluded from fig. 3 .

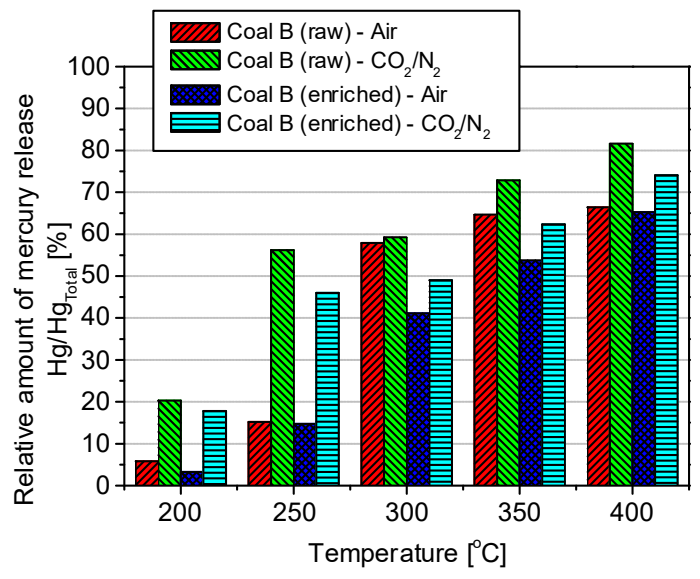

Figure 3. Relative amount of mercury release in selected temperature for coal B
The highest increase was noted, as in the case of coal A for a temperature of $250^{\circ} \mathrm{C}$, was roughly $55 \%$ coal B (raw) and $45 \%$ of coal $\mathrm{B}$ (enriched). For other temperatures also noted an increase in the amount of mercury released, but won't as large as at $250^{\circ} \mathrm{C}$. For the temperature of $350^{\circ} \mathrm{C}$ the amount of released mercury was roughly $75 \%$ (coal B - raw) and 65\% (coal $\mathrm{B}$ - enriched). For the highest temperature $\left(400^{\circ} \mathrm{C}\right)$ the amount of mercury released was more than $80 \%$ (coal B - raw) and roughly $75 \%$ (coal B - enriched).

\subsection{The loss of volatile matter during LT3}

Except from research of amount mercury released it was also conducted research caused degradation of the fuel subjected to LT3. We investigated the loss of volatile matter (VM) from the various coals as well as change of higher heat value (HHV) and the content of the carbon element in coals. The relative amount of volatile matter loss of were calculated from the difference in the volatile matter content in coal before LT3 and after treatment. In the case of coal A (raw) (fig. 4) at temperatures up to $350^{\circ} \mathrm{C}$ the amount of VM loss didn't exceed $13 \%$, regardless of the used atmosphere. Only at a temperature of $400^{\circ} \mathrm{C}$ the amount of VM loss of were about $20 \%$ (for air atmosphere), and about $15 \%$ in the atmosphere of $\mathrm{CO}_{2} / \mathrm{N}_{2}$. The coal A (enriched) amount of VM loss were higher roughly $13 \%$ for a temperature of $250^{\circ} \mathrm{C}$ and atmospheric air, about $15 \%$ in temperature of $350^{\circ} \mathrm{C}$ and about $20 \%$ in $400^{\circ} \mathrm{C}$. Change of atmosphere for coal A (enriched) caused a reduction in the amount of VM loss for temperatures $250-300^{\circ} \mathrm{C}$, and a slight increase for the top two temperatures 350 and $400^{\circ} \mathrm{C}$.

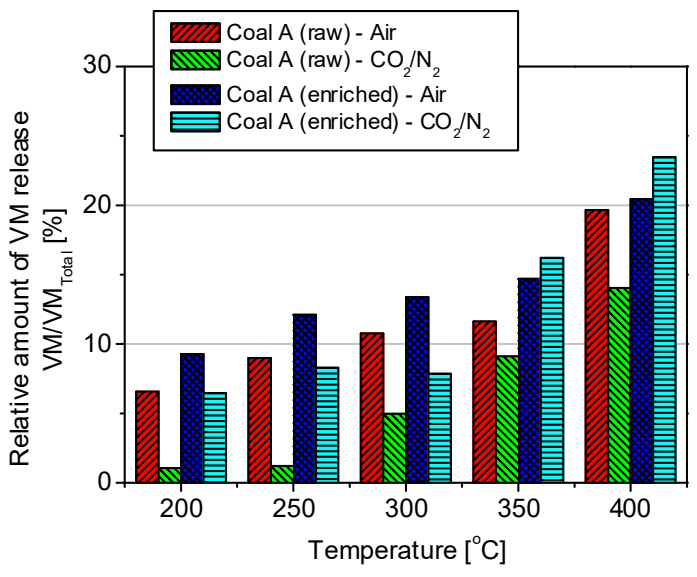

Figure 4. Relative amount of VM release in selected temperature for coal A

For coal B (raw and enriched) (fig. 5) the quantity of VM loss were about $10-12 \%$ for both types of coal B (raw and enriched) at temperatures $200-300^{\circ} \mathrm{C}$. Higher amount of $\mathrm{VM}$ were released until at $350^{\circ} \mathrm{C}$ and it were roughly $15 \%$ for both types of coal $\mathrm{B}$ (raw and enriched). In the highest temperature of $400^{\circ} \mathrm{C}$ the amount of VM released were $18-22 \%$ for both types of coal B (raw and enriched). 


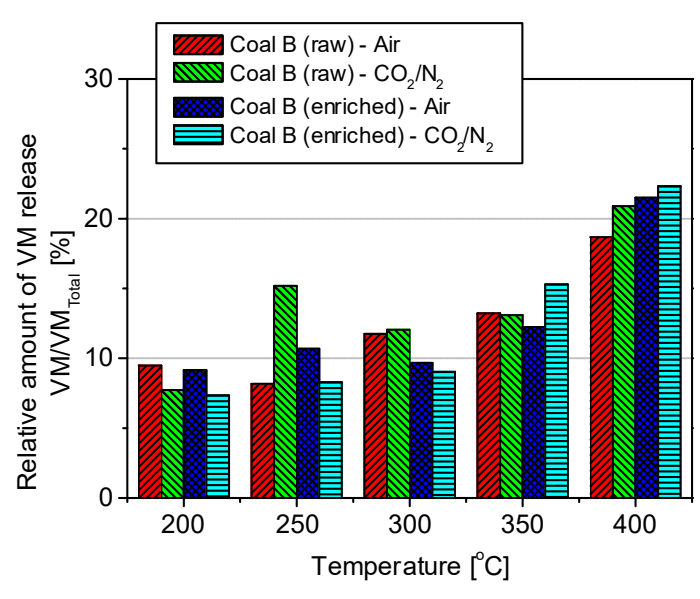

Figure 5. Relative amount of VM release in selected temperature for coal B

\subsection{The loss of higher heat value during LT3}

In the case of higher heat value (HHV) change for coal A (raw) (fig. 6) in air atmosphere, it was about $7 \%$ at $300^{\circ} \mathrm{C}$ and about $9 \%$ at $350^{\circ} \mathrm{C}$ and roughly $12 \%$ for $400^{\circ} \mathrm{C}$. Changing the atmosphere for a mixture of $\mathrm{CO}_{2} / \mathrm{N}_{2}$ significantly reduced the loss of HHV to a level of $8 \%$ at $400^{\circ} \mathrm{C}$.

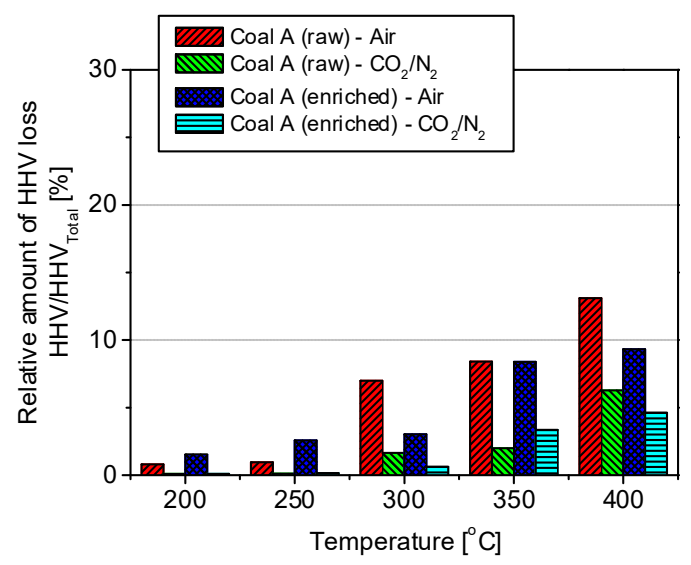

Figure 6. Relative amount of HHV loss in selected temperature for coal A

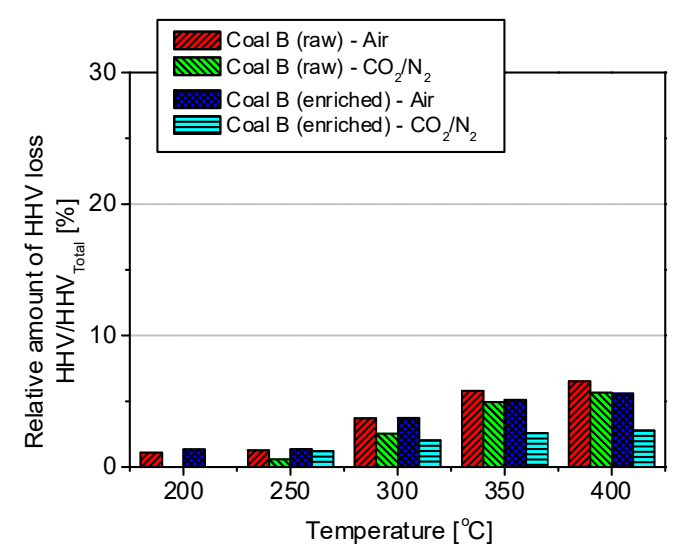

Figure 7. Relative amount of HHV loss in selected temperature for coal B
Also, in the case of coal A (enriched) atmosphere substitutions reduced the loss expressed by HHV from $8 \%$ at a temperature of $350^{\circ} \mathrm{C}$, up to about $4 \%$, at a temperature of $400{ }^{\circ} \mathrm{C}$ from about $9 \%$ to about $5 \%$.

In the case of coal B (raw and enriched) (fig. 7) change of atmosphere wasn't caused such significant changes as in the case coal A. For the highest temperatures of 350 and $400^{\circ} \mathrm{C}$, it was roughly $8 \%$, regardless of the atmosphere and the type of coal.

\subsection{The loss of carbon during LT3}

The figures 8-9 shown the change in the content of the carbon element as a result of LT3 processing of individual coals. Changes in the content of the element $\mathrm{C}$ in the coals $\mathrm{A}$ and $\mathrm{B}$ (raw and enriched) were very similar. For the temperature of $250^{\circ} \mathrm{C}$ in the case of coal A loss about $5 \%$ of the element $\mathrm{C}$ (for both raw and enriched), and in the case of coal $\mathrm{B}$ this loss was approximately 3\%. At temperatures $350-400^{\circ} \mathrm{C}$ amount of element $\mathrm{C}$ loss were about $9 \%$ in the case of coal A, and about $8 \%$ in the case of coal B. In both coals could be seen that in enriched coals samples amount of element $\mathrm{C}$ loss were less than that in raw coal. Also, in the case of enriched coals changed of atmosphere from air to mixture of $\mathrm{CO}_{2} / \mathrm{N}_{2}$ decreased the amount of element $\mathrm{C}$ loss.

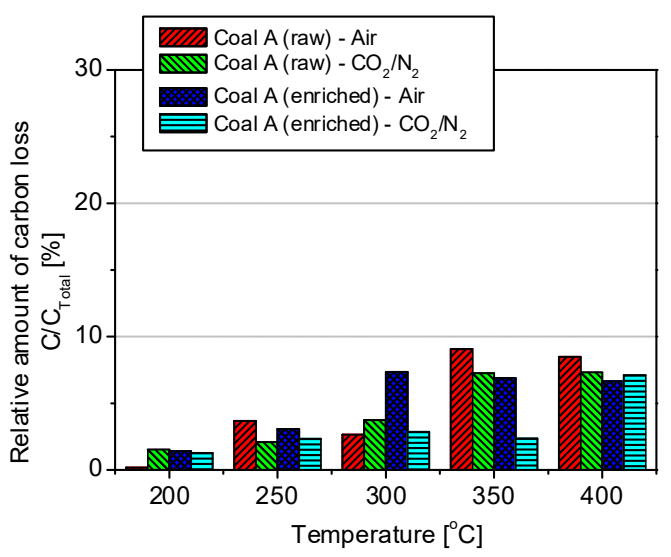

Figure 8. Relative amount of carbon loss in selected temperature for coal A

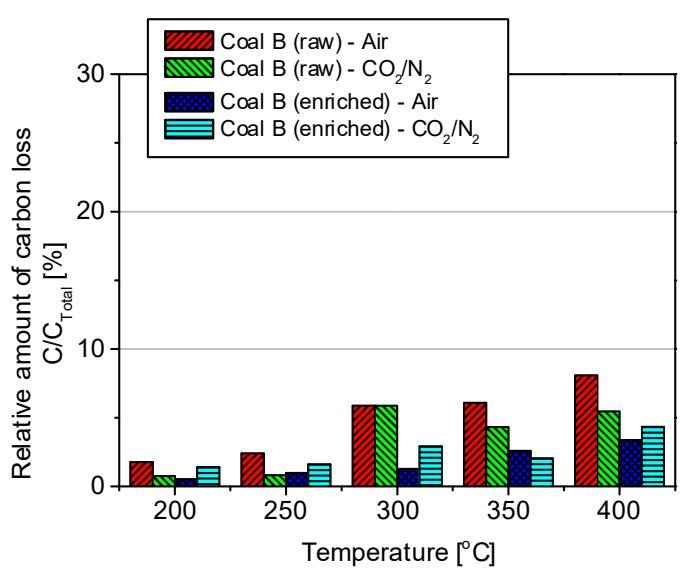

Figure 9. Relative amount of carbon loss in selected temperature for coal B 


\section{Summary}

The results of the research indicate that low-temperature thermal treatment of coals can remove significant amounts of mercury from coal. In the case of coal A maximum degree of mercury release was $95 \%$ (enriched coal, atmosphere of $\mathrm{CO}_{2} / \mathrm{N}_{2}$ ) and for coal B - 83\% (raw coal, atmosphere of $\mathrm{CO}_{2} / \mathrm{N}_{2}$ ). The amount of mercury release from the raw coals were in most cases bigger than that for the enriched coals. This is probably due to the fact that enriched coals generally contain less mercury than the raw coals, caused by the release of some mercury in the fuel enrichment processes. A greater amount of mercury released was especially visible in the case of temperatures below $300^{\circ} \mathrm{C}$. The amount of mercury released in the atmosphere of $\mathrm{CO}_{2} / \mathrm{N}_{2}$ was greater than in air, which was particularly evident at temperatures below $300^{\circ} \mathrm{C}$ for both coals A and B. The amount of volatiles released during LT3 process may seem high, , but as mentioned, it is possible to such lead a process that after the removal of mercury from process gases from LT3 VM could be recycled to the combustion chamber for combustion. This will limit the losses caused by this process, and at the same time improve the combustion of partially degassed coal. LT3 impact on the HHV of coals was approximately $10 \%$ for the temperature $400^{\circ} \mathrm{C}$ - in the case of coal A in air atmosphere, changing atmosphere for a mixture of $\mathrm{CO}_{2} / \mathrm{N}_{2}$ caused a loss of roughly $6 \%$ of the HHV. In the case of coal B changed of atmosphere also caused a reduction in HHV loss to a level of about $4 \%$ - in the case of enriched coal, and about $6 \%$ for raw coal. The effect of changing atmosphere on carbon loss was also observed. In the case of the raw coal A and B, there was a reduction, but in the case of enriched coals $\mathrm{A}$ and $\mathrm{B}$ the change of atmosphere caused minor increase in carbon loss.

\section{Acknowledgements}

This article is part of the project Programme for Applied Research: Develop a database of mercury in national coals, technical guidance of its further reduction with defining benchmarks for mercury national emission factors - Hg Base (PBS2/A2/14/2013).

\section{References}

1. United Nations Environmental Programme, Global Mercury Assessment, UNEP Chemicals, Geneva, 2013

2. Z. Grudziński, 2015; Fakty: Węgiel - Energetyka w Polsce, http://min-pan.krakow.pl/zaklady/zrynek/cf_we, [online: 20.04.2016]

3. Ya. E. Yudovich, M.P. Ketris, Int. J. Coal. Geol. 62 (2005)

4. K. Wojnar, J. Wisz, Mercury In Polish Power Sector, Energetics 4 (2006) (in Polish)

5. M. Wichliński, R. Kobyłecki, Z. Bis, Arch. Environ. Prot. 39, 2 (2013)

6. B. Klojzy-Karczmarczyk, J. Mazurek, Gospodarka Surowcami Mineralnymi, 29, 4 (2013)

7. I. Pyka, K. Wierzchowski, Arch. Min. Sci., 55, 2 (2010)

8. A. Glodek, J.M. Pacyna, Atmos. Environ. 43 (2009)
9. M. Wichliński, R. Kobyłecki, Z. Bis, Polityka Energetyczna 15, 4 (2012) (in polish)

10. M. Wichliński, R. Kobyłecki, Z. Bis, Polityka Energetyczna 14, 2 (2011) (in polish)

11. Ł. Uruski, J. Górecki, M. Macherzyński, T. Dziok, J. Gołaś, Fuel Process. Technol. 140 (2015)

12. T. Dziok, A. Strugała, A. Rozwadowski, A. Okońska, Przemysł Chemiczny 93, 12 (2014)

13. M. Wichliński, R. Kobyłecki, Z. Bis, Fuel Process. Technol. 119 (2014)

14. A. Iwashita, S. Tanamachi, T. Nakajima, H. Takanashi, A. Ohki, Fuel 83 (2004)

15. A. Ohki, K. Sagayama, S. Tanamachi, A. Iwashita, T. Nakajima, H. Takanashi, Powder Technol. 180 (2008)

16. F. Guffy, A. Bland, Fuel Process. Technol. 85 (2004)

17. R. Zarzycki, M. Wichliński, Polityka Energetyczna 17, 4 (2014) (in polish)

18. S. Sholupov, S. Pogarev, V. Ryzhov, N. Mashyanov, A. Stroganov, Fuel Process. Technol. 85 (2004) 